\title{
Major histocompatibility complex class I evolution in songbirds: universal primers, rapid evolution and base compositional shifts in exon 3
}

Genes of the Major Histocompatibility Complex (MHC) have become an important marker for the investigation of adaptive genetic variation in vertebrates because of their critical role in pathogen resistance. However, despite significant advances in the last few years the characterization of MHC variation in non-model species still remains a challenging task due to the redundancy and high variation of this gene complex. Here we report the utility of a single pair of primers for the cross-amplification of exon 3 of of the third exon of MHC class I genes, which that encodes for a the more polymorphic half large part of the peptide-binding region of the peptide-binding region (PBR), multiple MHC class I loci in oscine passerines (songbirds; Aves: Passeriformes), a group especially challenging for MHC characterization due to the presence of large and complex MHC multigene families. In our survey, although the primers failed to amplify exon 3 from two suboscine passerine birds, they amplified exon 3 of multiple MHC class I genes in all 16 species of oscine songbirds tested , belonging to 14 different families, yielding a total of 120 sequences. The 16 songbird species belong to 14 different families, primarily within the Passerida, but also in the Corvida. Using a conservative approach based on the analysis of cloned amplicons $(n=16)$ from each species, we found between 3 and $10 \mathrm{MHC}$ sequences per individual. Each allele repertoire was highly divergent, with the overall number of polymorphic sites per species ranging from 33 to 108 (out of 264 sites) and the average number of nucleotide differences between alleles ranging from 14.67 to 43.67 . Our survey in songbirds allowed us to compare macroevolutionary dynamics of exon 3 between songbirds and non-passerine birds. We found compelling evidence of positive selection acting specifically upon peptide-binding codons across birds, and we estimate the strength of diversifying selection in songbirds to be about twice that in non-passerines. Analysis using comparative methods suggest weaker evidence for a higher GC content in the $3^{\text {rd }}$ codon position of exon 3 in non-passerine birds, a pattern that contrasts with among-clade GC patterns found in other avian studies and may suggests different mutational mechanisms. Our primers represent a useful tool for the characterization of functional and 
evolutionarily relevant MHC variation across the hyperdiverse songbirds. 
1 Revised for PeerJ

2

3 Major Histocompatibility Complex class I evolution in songbirds:

4 universal primers, rapid evolution and base compositional shifts in

5

exon 3

6 MIGUEL ALCAIDE*, MARK LIU and SCOTT V. EDWARDS

Department of Organismic and Evolutionary Biology and Museum of Comparative Zoology

Harvard University

26 Oxford Street

Cambridge, MA 02138

USA

12 *Present address: Department of Zoology, University of Brithish Columbia, Vancouver, B.C., Canada

13 Corresponding author:

14 Dr. Scott Edwards (sedwards@fas.harvard.edu)

15 Department of Organismic and Evolutionary Biology

16 Harvard University

1726 Oxford Street

18 Cambridge, MA 02138

19 USA

20 Phone: (+1) 6173848082

21 Fax: (+1) 6174955667

22 


\section{ABSTRACT}

2 Genes of the Major Histocompatibility Complex (MHC) have become an important marker for

3 the investigation of adaptive genetic variation in vertebrates because of their critical role in

4 pathogen resistance. However, despite significant advances in the last few years the

5 characterization of MHC variation in non-model species still remains a challenging task due to

6 the redundancy and high variation of this gene complex. Here we report the utility of a single

7 pair of primers for the cross-amplification of the third exon of MHC class I genes, which

8 encodes the more polymorphic half of the peptide-binding region (PBR), in oscine passerines

9 (songbirds; Aves: Passeriformes), a group especially challenging for MHC characterization due

10 to the presence of large and complex MHC multigene families. In our survey, although the

11 primers failed to amplify exon 3 from two suboscine passerine birds, they amplified exon 3 of

12 multiple MHC class I genes in all 16 species of oscine songbirds tested, yielding a total of 120

13 sequences. The 16 songbird species belong to 14 different families, primarily within the

14 Passerida, but also in the Corvida. Using a conservative approach based on the analysis of

15 cloned amplicons $(n=16)$ from each species, we found between 3 and 10 MHC sequences per

16 individual. Each allele repertoire was highly divergent, with the overall number of polymorphic

17 sites per species ranging from 33 to 108 (out of 264 sites) and the average number of nucleotide

18 differences between alleles ranging from 14.67 to 43.67 . Our survey in songbirds allowed us to

19 compare macroevolutionary dynamics of exon 3 between songbirds and non-passerine birds. We

20 found compelling evidence of positive selection acting specifically upon peptide-binding codons

21 across birds, and we estimate the strength of diversifying selection in songbirds to be about twice

22 that in non-passerines. Analysis using comparative methods suggest weaker evidence for a

23 higher GC content in the $3^{\text {rd }}$ codon position of exon 3 in non-passerine birds, a pattern that 
1 contrasts with among-clade GC patterns found in other avian studies and may suggests different

2 mutational mechanisms. Our primers represent a useful tool for the characterization of

3 functional and evolutionarily relevant MHC variation across the hyperdiverse songbirds.

4 Keywords: Major histocompatibility complex, 454 pyrosequencing, diversifying selection,

5 adaptive variation, immune response, pathogen-mediated selection, GC content, comparative 6 methods

\section{INTRODUCTION}

9 Genes of the Major Histocompatibility Complex (MHC) have become one of the most sought-after molecular markers for the investigation of adaptive genetic variation in vertebrates

11 (e.g. Eizaguirre et al. 2012; Kamath \& Getz 2011; Kubinak et al. 2012; Radwan et al. 2012).

12 MHC genes are known to play a critical role during the development of immunity against

13 invading and potentially harmful pathogens. The cell-surface proteins encoded by MHC genes

14 bind and present short peptides (antigens) derived from the processing of pathogens to

15 lymphocyte T-cells, which triggers the adaptive branch of the immune system (Iwasaki \&

16 Medzhitov, 2010). MHC genes are also thought to play important roles in avian mate choice,

17 although the conclusions of various studies have been mixed, in part because of the complexity

18 of this redundant multigene family (e.g. Strandh et al. 2012; Bollmer et al. 2012; Juola \&

19 Dearborn 2011; Knafler et al. 2012; Ekblom et al. 2004; Westerdahl, 2004).

20 MHC molecules have been traditionally classified into two major groups on the basis of

21 the origin of the antigens presented, although some degree of cross-presentation between MHC

22 classes is now currently assumed (e.g. Iwasaki \& Medzhitov, 2010). Typically, MHC class I

23 molecules are monomeric proteins known to mostly present antigens derived from intracellular 
1 pathogens (such as viruses) while MHC class II molecules are dimeric proteins deploying

2 antigens from extracellular pathogens such as bacteria (reviewed by (Sommer, 2005). Given the

3 extraordinary richness and diversity of continuously evolving pathogens in the environment, it is

4 not surprising that the MHC harbors the most polymorphic genes described thus far, with some

5 loci, such as the human HLA-B locus, possessing more than 2,000 alleles (de Bakker \&

6 Raychaudhuri 2012). The maintenance of such astonishing diversity is believed to be driven

7 primarily by two main types of balancing selection: heterozygote advantage, by which

8 heterozygous individuals respond better to infection than homozygous individuals, and

9 frequency-dependent selection, by which rare, low-frequency alleles might provide a selective

10 advantage once pathogens have found a way to elude the most common immune defense alleles

11 in the population. The evolutionary implications of MHC variation during the pathogen-host

12 arms race have been widely investigated across a large variety of taxa. As a result, MHC genes

13 have been of great interest in evolutionary biology and conservation genetics, as the capability of

14 species and populations to counter and adapt to novel pathogen menaces is believed tightly

15 linked to their degree of MHC variability (see Piertney \& Oliver 2006; Sommer, 2005; Spurgin

16 et al. 2011), but see also (Gangoso et al. 2012; Radwan, Biedrzycka \& Babik 2010, Westerdahl

17 et al. 2012).

18 Despite their great interest and potential for ecological immunology, the isolation and

19 characterization of MHC genes in non-model species still remains a challenging and

20 time-consuming task. Until recently, the description of MHC genes in birds, particularly for class

21 I genes, was mostly restricted to galliform species and a very few species of songbirds (reviewed

22 by Hess \& Edwards 2002; Westerdahl, 2007). The last few years have nevertheless witnessed

23 great progress regarding the isolation and characterization of MHC genes in non-model avian 
1 species, particularly across the avian MHC class II B multigene family (e.g. Alcaide, Negro and

2 Edwards 2007; Burri et al. 2008; Canal et al. 2010; Ekblom, Grahn and Höglund 2003; Li, Zhou

3 and Chen 2011; Silva \& Edwards 2009; Strandh et al. 2011). Additionally, significant advances

4 in genotyping protocols for complex multigene families like the MHC (reviewed by Babik,

5 2010) have facilitated the MHC studies in general, particularly in songbirds displaying large

6 number of MHC gene paralogs (e.g. Bollmer et al. 2010; Sepil et al. 2012; Zagalska-Neubauer

7 et al. 2010). Studies addressing MHC class I variability in birds are, however, less numerous or

8 phylogenetically diverse than those for MHC class II B genes (see recent examples in Cloutier,

9 Mills and Baker 2011; Promerova, Albrecht and Bryja 2009; Sepil et al. 2012, Westerdahl, 2004)

10 in part almost certainly due to the lack of suitable primers for the cross-amplification of

11 candidate loci across species (see however Alcaide et al. 2009). Here, we describe the utility of a

12 single pair of primers for the cross-amplification of MHC class I loci across a large avian order

13 (Aves: Passeriformes), which includes more than half of known avian species, in an effort to

14 facilitate the study of MHC variation in non-model avian species. From the two exons of MHC

15 class I genes (exon 2 and 3) that comprise the peptide-binding region (PBR), we focused on exon

163 , in part because it has generally been found to be the more polymorphic of the two (e.g.

17 Cloutier et al. 2011). Putting our data together with published class I sequences from

18 non-passerine birds, we analyzed the macroevolution of both rates of adaptive evolution and base

19 compositional shifts as windows into the selective and mutational pressures experienced by

20 songbird class I genes.

21

22 MATERIALS AND METHODS

23 We used the QIAGEN-DNeasy Blood \& Tissue Kit (Qiagen, CA, USA) to obtain genomic DNA 
1 from blood samples collected in the field and tissue samples from the Museum of Comparative

2 Zoology at Harvard University (Cambridge, MA, USA; Animal protocol number AEP 24-06)

3 following the manufacturer's protocol. The list of songbird species investigated is shown in Table

4 1. We initially amplified the entire coding sequence of exon 3 of MHC class I genes and a small

5 part of the flanking intronic regions (see Fig. 1) in two house finches (Haemorhous mexicanus)

6 and two eastern bluebirds (Sialia sialis) using primers HN34 (5'-

7 CCATGGGTCTCTGTGGGTA-3') and HN45 (5'- CCATGGAATTCCCACAGGAA-3') from

8 Westerdahl et al. (2004). Although these primers were originally designed for the isolation of

9 MHC class I loci in great reed warblers (Acrocephalus arundinaceus) they have proven

10 successful in the isolation of MHC class I sequences in other passerine species (e.g. Promerova,

11 Albrecht and Bryja 2009; Sepil et al. 2012). PCR amplification was carried out using a PTC-100

12 Programmable Thermal Controller (MJ research, MA, USA) in a final volume of $25 \mu \mathrm{l}$

13 containing 1 unit of EconoTaq DNA polymerase (Lucigen Corporation, Middleton, WI, USA), 1

$14 \mathrm{x}$ PCR buffer (Lucigen), $1 \mathrm{mM} \mathrm{MgCl} 2,10$ pmoles of each primer, $0.2 \mathrm{mM}$ of each dNTP, $10 \mu \mathrm{g}$ of

15 BSA, 5\% DMSO, and approximately 10-30 ng of DNA. The cycling protocol consisted of an

16 initial denaturation step of $95^{\circ}$ during 4 min, followed by 35 cycles of $95^{\circ} \mathrm{C}$ for $45 \mathrm{~s}, 55^{\circ} \mathrm{C}$ for

$1745 \mathrm{~s}$ and $72{ }^{\circ} \mathrm{C}$ for $45 \mathrm{~s}$ plus a final extension step of $72{ }^{\circ} \mathrm{C}$ during 4 min. After visualization of

18 PCR products in 1\% agarose gels stained with SYBR safe (Invitrogen, CA, USA) we cloned

19 fragments using the StrataClone PCR cloning kit (Agilent Technologies, Inc. CA, USA) and

20 inserts of the expected size (around 350 bp) were re-amplified using M13 primers, purified with

21 ExoSAP-IT reagent (Affymetrix, CA, USA) and sequenced with M13 primers and BigDye 3.1

22 reagents (Applied Biosystems, CA, USA) supplemented with BDX64 buffer (MCLAB, CA,

23 USA) according to the manufacturer's protocols. Sixteen positive clones from each of the two 
1 birds were selected for sequencing. Fluorescently labeled fragments were resolved into an

2 Applied Biosystems 3730 xl DNA Analyzer (Applied Biosystems, CA, USA). The sequences

3 obtained from house finches and eastern blue birds were aligned in BioEdit ver 7.0 (Hall 1999)

4 and Geneious R6 (Drummond et al. 2011). New degenerate primers sitting on the boundaries of

5 exon 3 were designed following the alignment of house finch and bluebird MHC class I

6 sequences. These primers were MhcPASCI-FW 5'- CSCSCAGGTCTSCACAC- 3' and

7 MhcPASCI-RV 5'- CWCARKAATTCTGYTCHCACC -3' (Fig. 1). Primer MhcPASCI-FW is

8 similar in its sequence to the primers HN36 and HN38 designed by Westerdahl et al. (2004) but

9 our primer is more degenerated and 3 nucleotides shorter in the $3^{\prime}$ end (the last nine nucleotides

10 of the primer sit into the coding sequence of exon 3). The utility of this primer pair was tested in

11 each of the 16 songbird species from 14 different taxonomic families, as well as two suboscine

12 passerine species, a manakin (Pipiridae) and a New World Flycatcher (Tyrranidae). The PCR

13 protocol used was the same as that described above for the primer pair HN34/HN45. Likewise,

14 PCR products were cloned and sixteen positive bands per species or individual sequenced with

15 M13 primers as described above. Sequences were again edited and aligned in BioEdit and

16 Geneious R6 (Drummond et al. 2011). We then searched for different, putative alleles within

17 each individual. Given the low number of clones screened we only considered as different,

18 presumably functional alleles, those DNA sequences differing in at least three nucleotide

19 positions and not showing stop codons or disrupted reading frames. These criteria will minimize

20 the impact of PCR and sequencing artifacts in our allele repertoire but may also underestimate

21 the number of alleles per individual (e.g. when true alleles differed in just one nucleotide

22 positions but they are not found in more than one clone each). All sequences fitting these criteria

23 have been deposited into the GenBank public domain (see results). Putative pseudogenes and 
1 those sequences suspected to be mosaic or chimeric sequences were discarded. In a study

2 focused on population genetics, the genotyping of MHC loci across large complex multigene

3 families requires more stringent criteria and protocols to define true alleles than those described

4 in this study (e.g. Lenz \& Becker 2008, Sepil et al. 2012). Here our purpose was to produce a

5 first glimpse of the utility of our primers and broad macroevolutionary patterns, but future

6 studies using our primers should more thoroughly analyze a MHC variability in particular

7 species with more stringent quality checks.

8 The MHC class I sequences here isolated plus additional exon 3 sequences from

9 non-passerine species downloaded from the public domain (see Supplementary file 1) were

10 aligned using the Muscle algorithm (Edgar, 2004) as implemented in TranslatorX, a codon-based

11 alignment algorithm (Abascal, Zardoya and Telford 2010), using default options. We built a

12 phylogenetic tree using the Neighbour-joining method (Saitou \& Nei 1987) as implemented in

13 Geneious R6 (Drummond et al. 2011) using an optimal substitution model (Tamura-Nei model +

14 gamma $=0.78$ in this case) from ModelTest v. 3.5 (Posada and Crandall 1998). An MHC class I

15 exon 3 sequence of the Balsas armed lizard (Ctenosaura clarkil; GenBank Acc. No. EU839667)

16 was used as outgroup. Branch support was evaluated by 1,000 bootstrap replicates. We verified

17 that the major branches in this tree, including the strongly supported branches leading to the

18 songbird sequences and to several of the major clades of sequences were present when using the

19 maximum likelihood method as implemented in Phyml v. 3.0, using SPR tree searching and a

20 HKY model of substitution with estimated variation in rates among sites (Guindon et al. 2010).

21 The phylogenetic relationships among songbird MHC class I sequences were also visualized

22 through a neigbor-net network built in Splitstree 4.0 (Huson \& Bryant 2006) according to

23 Kimura-2-parameter distances. We tested for a significant clustering of MHC sequences by 
1 species using a permutation test in MacClade in which we compared the observed number of

2 parsimony changes in a character coded as species designation on the best tree with the

3 distribution observed on 1000 random trees. Non-synonymous $\left(\mathrm{d}_{\mathrm{n}}\right)$ and synonymous substitution

4 rates $\left(d_{s}\right)$ were calculated in MEGA ver 5.0 (Tamura et al. 2011) according to the modified

5 Nei-Gojorobi method with Jukes-Cantor correction and 1,000 bootstrap replicates for variance

6 estimation. Two analyses were carried out, one including only putative PBR codons and another

7 including the remaining codons. Codons were labeled as PBR or non-PBR in accordance with

8 previously documented patterns of positive selection across the avian MHC class I (see

9 Balakrishnan et al. 2010, Alcaide et al. 2009), which also suggested large overlapping between

10 the PBR of the human MHC class I molecule (Björkman et al. 1987, Saper et al. 1991) and

11 homologous sites in birds. The exon 3 codons classified as PBR-codons were

$125,7,8,9,23,25,38,60,61,62,65,66,68$ and 73.

13 We carried out an independent analysis of codon substitution using the codeml software

14 in the PAML package v.4.4 (Yang 2007). Specifically we used the branch-site and clade tests

15 (models A, C and D, see Bielawski \& Yang 2004; Yang, Wong and Nielsen 2005), focusing on

16 the branch leading to songbirds (model A), or the entire clade of songbirds (models C and D).

17 These models differ in their structure as well as in the assumptions about the values that specific

18 parameters can take. For example, in model A, the 'background' branch cannot have any sites

19 with values of $\omega$ greater than 1 , and the test focuses on a specific branch, in our case the single

20 branch leading to the passerine sequences. By contrast in both models $\mathrm{C}$ and $\mathrm{D}$, one class of

21 sites $\left(\omega_{0}\right)$ is constrained to fall below 1 . But other classes of sites $\left(\omega_{1}\right)$ are either constrained to

22 equal 1 (model C) or allowed to take on any positive value (model D). Models C and D both test

23 average rates across clades, rather than specific branches, but they differ in the statistical models 
1 assumed, with model C employing the more accurate Bayes-Empirical-Bayes (BEB) method,

2 rather than the naïve empirical bayes (NEB) approach (Bielawski \& Yang 2004; Yang, Wong and

3 Nielsen 2005). However all of these methods allowed us to assess those PBR codons

4 experiencing adaptive evolution without identifying them a priori.

We also noticed pronounced variation in GC content of the avian MHC class I sequences

6 across various groups, particularly in the $3^{\text {rd }}$ position of codons. Given that base compositional

7 variation is a consequence of a variety of molecular forces, such as recombination, gene

8 conversion and selection, this base compositional variation could be important for understanding

9 the evolutionary forces operating on avian MHC class I genes (Duret and Galtier 2009). To

10 quantify and better understand the dynamics of GC-content in avian MHC class I genes, we

11 analyzed the phylogenetic signal in GC content using a comparative method (see Thomas, Meiri

12 and Phillimore 2009) that is well suited to testing for the significance of means and variances of

13 continuous characters among clades under a Brownian motion model. Base compositional

14 evolution in DNA sequences has often been challenging to analyze because standard

15 phylogenetics packages that allow this calculation often perform standard, non-phylogenetic tests

16 of significance, which are inappropriate (e.g., PAUP*; Swofford 2002). The likelihood method

17 of Thomas et al (2009) (see also Thomas et al. 2006) is well suited for the analysis of

18 diversification of continuous phenotypic or genotypic traits. This approach is able to distinguish

19 between two possible causes of differences in means between groups: differences in rate of trait

20 evolution (as revealed by the Brownian variance of the trait) between groups without there being

21 differences in means, and true differences in means between groups, with or without differences

22 in rates of evolution. For these calculations we removed the outgroup and used an

23 ultrametricized tree using the penalized likelihood method of Sanderson (2002), using a value of 
12 for the smoothing parameter $\lambda$. The Brownian motion analysis was implemented in the

2 'motmot' package in R, version 1.0.1 (Thomas and Freckleton 2012).

3 Results

$4 \quad$ Versatile primers for songbirds: The primer pair MHCPasCI-Fw and MHCPasCI-Rv

5 successfully amplified multiple MHC class I sequences in all 16 songbird species tested in the 6 present study (Table 1, GenBank Acc. Nos. KC585518-KC585637, see also Supplementary file

7 2). The number of putatively functional MHC alleles ranged from 3 to 10 per individual. This is

8 surely an underestimate given the low number of clones screened per individual and the

9 possibility of confounding true alleles differing by less than 3 substitutions with PCR or

10 sequencing artifacts. However, genetic diversity within the allele repertoire isolated from the

11 same individual or species was high. The number of variable sites ranged from 33 to 108 (out of

12 264) and the average number of nucleotide differences between putative alleles or loci within

13 species ranged from 14.67 in the tropical gnatcatcher to 43.67 in the European Starling (Table 1).

14 Non-synonymous substitution rates commonly exceeded synonymous substitution rates at those

15 codons presumably comprising the peptide binding, while the contrary was the general pattern

16 outside PBR codons (Table 1). This finding is consistent with our having amplified functional

17 MHC genes subjected to positive, diversifying selection. The co-amplification of putative

18 pseudogenes, on the other hand, seemed to be common in the following species: blue-grey

19 tanager, stripe-breasted wren and American robin, while in the remaining species this

20 phenomenon appeared to be rare (Table 1). An alignment of the selected and presumably

21 functional MHC class I sequences is included as supplementary information (Supplementary file

22 1). Four out of the five MHC class I alleles that we isolated in the common yellowthroat (an

23 individual captured in Massachusetts, U.S.) are identical to some of the alleles previously

24 isolated in the same species (from a Wisconsin population, U.S.) by Bollmer et al. (2012) 
1 through a pyrosequencing approach (GenBank Acc. Nos. AFP1784, AFP17830, AFP17847 and

2 AFP17865, see Supplementary files 1 and 2). In addition, four out of the eight alleles that we

3 isolated in the house sparrow differed in no more than three amino acid positions from other

4 alleles previously isolated in this species by Bonneaud et al. (2004) and Loiseau et al. (2008)

5 (GenBank Acc. Nos. AAQ22383, ABO15711). These similarities lend confidence to our results

6 and suggest we have in some cases amplified the same or very similar loci. The absence of any

7 identical alleles in House Sparrows is likely due to the different geographic origin of the House

8 Sparrow individual here investigated (Massachussets, U.S.) versus the House Sparrows

9 individuals genotyped in the studies by Bonneaud et al. (2004) and Loiseau et al. (2008) (Europe,

10 see for instance Alcaide et al. 2008 for marked genetic structuring at the MHC). After repeated

11 attempts at amplification, we nonetheless found out that our primers do not amplify a

12 homologous MHC class I fragment from the two suboscine species that we investigated, a

13 manakin (Pipiridae) and a New World Flycatcher (Tyrranidae).

14 Phylogenetic relationships: The phylogenetic relationships among the MHC class I

15 sequences isolated in this study plus additional exon 3 sequences isolated in other avian species

16 are depicted in Figure 2. The resulting tree defined two main clades, one including all songbirds

17 and the other encompassing the rest of bird species, including chicken, Anseriformes, diurnal

18 birds of prey, petrels, seagulls, falcons and kestrels. We also found that there was strong support

19 for clustering of sequences for various higher clades, such as Anseriformes (Mallard and goose

20 in our data set), Falcons/Kestrels, diurnal birds of prey+ gull + petrel, and chicken. The lack of

21 complete clustering according to species for many of the 17 nonpasserine or 16 passerine species

22 is not surprising given the expected impact of trans-species polymorphisms across the MHC in

23 general (e.g. van Oosterhout, 2009) and the complex nature of the songbird MHC class I 
1 multigene family in terms of paralogs. Still, using the permutation test, we found that the

2 observed number of parsimony transitions of a character (x) labeled as species designation in

3 both songbirds $(\mathrm{x}=33)$ and non-passerines $(\mathrm{x}=18)$ was significantly lower than that observed

4 among 1000 random trees (passerines: range $x=99-115$ steps; non-passerines, range $x=62-76$;

5 both groups, $\mathrm{P}<0.001$ ), suggesting significant clustering by species. For example, the 15

6 sequences from the two tit species from the database all clustered together (although not by

7 species), as did the 6 gnatcatcher, 6 vireo and 9 waxwing sequences (see Supplementary Figure 1

8 for a more detailed tree, see also Figure 3). On the other hand, the neighbor-net depicted in

9 Figure 3 shows a complex network with multiple reticulate events both within and among

10 species, particularly in a cluster of blackbird, tanager and yellowthroat sequences. Evidence for

11 recombination using the SplitsTree Phi test was not significant $(p=0.09)$ across the entire

12 songbird MHC class I data set, although this test is ideally applied to a large set of MHC

13 sequences isolated from the same or closely related species. Qualitatively, our results suggest a

14 role for recombination during the evolution of the MHC class I multigene family in songbirds.

Greater selection intensity in the PBR of songbird MHC class I: We analyzed patterns of

nucleotide substitution using MEGA and PAML. When estimating $\omega$ using the modified Nei and

17 Gojobori (1986) method in MEGA, we found evidence for rates of diversifying selection acting

on PBR codons in songbirds about twice as great as those found in non-passerine birds (Table 2).

19 For non-PBR codons, the differences in $\omega$ between clades are less pronounced (Table 2). Rates

20 of synonymous substitution $\left(\mathrm{d}_{\mathrm{s}}\right)$ appear to be slightly higher in non-passerine birds, both in and

21 outside the PBR, suggesting that it is not solely substitution rates or shorter generation time that

22 is driving the difference in $\omega$ between the groups. We found similar patterns when the data were

23 analyzed using PAML. We found clear evidence for adaptive evolution in songbirds, as 
1 evidenced by the lower likelihood score for models that included adaptive evolution compared to

2 those that did not (model 1 vs. $2: 2 *$ difference in $\operatorname{lnL}=2$ 291.7; $\mathrm{LRT}$, df $=2, \mathrm{p}<0.0001$ ); model 7

3 vs. $8,2 *$ difference in $\ln L=299.08, \mathrm{df}=2, \mathrm{p}<0.0001)$. We next examined branch-site and clade

4 models. In model A, the estimated value of $\omega$ for class 2 a sites $\left(0<\omega_{0}<1\right.$ background vs. $\omega_{2} \geq 1$

5 foreground) was about 10 times higher in songbirds $\left(\omega_{2}\right)$ than in non-passerines $\left(\omega_{0}\right)$. For class

$62 \mathrm{~b}$ sites ( $\omega_{1}=1$ background vs. $\omega_{2} \geq 1$ foreground), rates of adaptive evolution were about four

7 times higher in songbirds $\left(\omega_{2}\right)$ than in non-passerines $\left(\omega_{1}\right)$. Model A identified 11 codons with

8 high probabilities of adaptive evolution (see Fig. 4), whether with uniform rates (model 2) or a

9 gamma distribution of rates (model 8) among sites was assumed. This set of codons (numbers 5 ,

$107,9,23,25,48,62,65,66,73$ and 83$)$ shared nine codons (5,7,9,23,25,62,65,66 and 73) with

11 those designated in the MEGA analysis. Codons 48 and 83 were subjected to positive selection

12 according to PAML analysis but were not labeled as PBR codons during MEGA analysis. On the

13 other hand, codons 9, 60, 61 and 68, which were labeled as PBR codons in the MEGA analysis,

14 are in close proximity (within one or two codons) to one of the positively selected codons

15 revealed by PAML analyses. In model D, passerines exhibited a level of diversifying selection

$16\left(\omega_{2}\right)$ again about four times higher in passerines than in non-passerines. Model C was the only

17 model that suggested an equivalence of diversifying selection in passerines and non-passerines,

18 with the value of site class 2 (freely varying $\omega_{2}$ ) being approximately equal in passerines and

19 non-passerines.

20 Shifts in GC content between songbirds and non-passerines: We noticed conspicuous

21 differences in GC content of our exon 3 sequences between songbirds and non-passerines,

22 particularly for the $3^{\text {rd }}$ codon position (GC3) (Fig. 5). By a standard statistical test, the mean

23 GC3 content differed highly significantly between songbirds and non-passerines (Welch's two 
1 sample t-test, $\mathrm{t}=10.3108, \mathrm{df}=223$, $\mathrm{p}$-value $<2.2 \mathrm{e}-16$; mean passerines $69.77 \%$, mean

2 non-passerines 77.58\%), although the GC content overall codon positions did not $(\mathrm{t}=-1.4671$, df

3 = 223, p-value $=0.1438$; mean passerines 57.23\%, mean non-passerines $56.71 \%$ ). We employed

4 the Brownian motion model of Thomas et al. 2009 to study the evolution of base composition in

5 our class I sequences while taking phylogeny into account. Surprisingly, using an

6 ultrametricized tree, we found that a model in which GC3 was assumed the same rates of

7 evolution and same mean between the two clades was the simplest explanation of the data as

8 assessed by its having the lowest value for the Akaike Information Criterion (AIC; Table 3).

9 Across all the tests, we found no evidence for differences in rates of evolution of GC content in

10 the two clades. However, we reasoned that the long branch leading to the songbird sequences

11 could be causing this lack of significance, because we would expect greater differences between

12 clades and greater total Brownian variance with a longer time period separating the two clades in

13 question. We found this to be the case; the significance of a difference in GC3 between songbirds

14 and non-passerines was dependent on the length of the branch leading to the passerine clade. If

15 this branch was cut in half, a model in which the two clades had different means was superior to

16 a model in which they had the same means, not only when rates of evolution were assumed to be

17 the same in the two clades, but even when rates of evolution were assumed to be different, in

18 which case different rates could possibly explain some of the differences in mean (Table 3).

19 Thus the degree to which songbird MHC class I $3^{\text {rd }}$ positions are deemed to differ in their GC

20 content depended on the length of the branch leading to songbirds. This uncertainty has

21 important implications for the analysis of continuous traits in birds.

22

23 Discussion 
1 The complexity of the songbird MHC class I multigene family documented here and in previous

2 studies (e.g. Westerdahl, 2004; Sepil et al. 2012; Bollmer et al. 2012) makes surveying MHC

3 variation through traditional cloning techniques challenging. Along with its ability to

4 cross-amplify multiple MHC class I loci across a wide diversity of species, an additional

5 advantage of our primer pair is the small size of the PCR amplicons ( $\sim 300 \mathrm{bp})$ that stills covers

6 almost the entire coding region of one of the exons comprising the class I PBR - short enough to

7 be amenable to next-generation sequencing but longer than most class I sequences currently

8 available in the data bases. These properties make our primers especially suitable for

9 cost-effective pyrosequencing approaches for genotyping large numbers of individuals (see

10 review by Babik, 2010).

11 The high number of divergent sequences isolated from single individuals in out study,

12 despite the low number of clones that we screened per individual, also suggests that our survey

13 was not preferentialy amplifying certain alleles or loci to an extreme degree. Equal amplification

14 of alleles is of great utility when attempting to discriminate between presumably true alleles and

15 those emerging from PCR and/or sequencing artifacts. The exon-intron boundaries where our

16 primers sit are expected to be relatively well conserved within and among related species

17 because their critical role in the process of intron splicing. This expectation would be consistent

18 with the successful cross-amplification and the retrieval of large allele repertoires with our

19 primers. That said, we cannot rule out the existence of polymorphisms in the priming sites that

20 cause poor or non-amplification of certain alleles/loci. Even so, the sequences obtained with our

21 primers are still useful, especially if used in conjunction with previously published primers in

22 other MHC class I regions (e.g. Westerdahl et al. 2004; Sepil et al. 2012), which together permit

23 evaluation of potential PCR biases in particular taxa. 
Our primers successfully amplified a large variety of species of oscine passerines,

2 including representatives from the infraorders Passerida and Corvida (see Barker et al. 2002 and

32004 for more details about phylogenetic relationships among passerines). Within Passerida we

4 amplified several members of the core Passeroidea and Muscicapoidea, as well as taxa outside

5 these clades, such as waxwings (Bombycillidae), New world Warblers (Parulidae), nuthatches

6 (Sittidae) and wrens (Troglodytidae). The red-eyed vireo (Vireonidae) is nevertheless the unique

7 representative of the clade Corvida in the present study, but because of its basal position within

8 Corvida we predict that these primers should work in other Corvida, such as crows and

9 bowerbirds. Our primers did not amplify, the homologous region from two suboscine passerine

10 species, a manakin (Pipridae) and a New World Flycatcher (Tyrranidae). Thus these primers

11 appear to be songbird-specific, rather than passerine-specific.

This songbird MHC class I data set, when combined with class I sequences from

13 non-passerines, afforded us a macroevolutionary view of MHC class I evolution in birds. We

14 found consistent evidence for stronger adaptive evolution in songbird than in non-passerine class

15 I sequences. The analysis using MEGA, and two of the three PAML models we used gave strong

16 evidence for a higher ratio of nonsynonymous to synonymous $(\omega)$ substitutions in the PBR,

17 whether or not PBR codons were chosen a priori. Paradoxically, the only model that did not

18 suggest higher adaptive evolution in the songbird PBR was model C of PAML, which suggested

19 that the intensity of selection in songbirds and non-passerines was approximately equal. Overall

20 we take these results as strong evidence that songbirds do exhibit a higher rate of adaptive

21 evolution than non-passerines.

22 This higher intensity of adaptive evolution in songbirds could be part of a general

23 syndrome of songbird evolution driven by their generally small body size, rapid rate of 
1 evolution, diversity of habitat occupancy and hence higher encounter rate with parasites. In

2 many studies of molecular evolution, passerines exhibit higher rates of evolution than do

3 non-passerines. This pattern has been attributed to several factors, especially the generation time

4 effect, with passerines having a larger number of generations per unit time than non-passerines.

5 Nam et al. (2010) found several predictors of synonymous and nonsynonymous substitution rates

6 in birds. For example, contrary to the predictions of the Hill-Robertson effect, which predicts a

7 positive relationship between the rate of nonsynonymous substitution and chromosome size (due

8 to the increased efficiency of purging presumably deleterious nonsynonymous substitutions on

9 highly recombining small chromosomes), they found a weak negative relationship between $\omega$

10 and chromosome size in chicken and zebra finch. The MHC class I region is on a

11 microchromosome in chicken, and the single functional class I gene in Zebra Finch is on the

12 smallest macrochromosome, chromosome 16 (Ekblom et al. 2011), which is still larger than a

13 microchromosome. Thus although MHC genes in both chicken and songbirds may be on small

14 chromosomes, their results do not clearly predict which lineage should show higher rates, or

15 indeed may predict that chickens should have higher rates than zebra finches, contrary to our

16 results. MHC class I pseudogenes, of which Balakrishnan et al. (2010) found several, are likely

17 dispersed on multiple chromosomes in zebra finch (Balakrishnan et al 2010; Ekblom et al. 2011).

18 Thus chromosome position cannot yet inform our understanding of rates of evolution in songbird 19 class I genes.

A more general explanation of higher intensities of selection in songbird MHC class I

21 genes may lie in their larger effective population sizes. The ease with which balancing selection

22 will act on MHC genes, without the negating effect of genetic drift, will depend on the effective

23 population size (Takahata 1990). Larger effective population sizes will allow for positive or 
1 balancing selection to act with greater efficiency than smaller effective population sizes; the

2 opposite trend is expected when selection is largely stabilizing or purifying (Welch et al. 2008).

3 Due to their smaller body sizes and shorter generation times, passerines almost certainly have a

4 higher average effective population size than do non-passerines. Ultimately the covariance

5 among all these variables may make it challenging to determine ultimate causes of stronger

6 selection in passerines at MHC class I genes.

$7 \quad$ The base composition of genes and lineages is an important window in to evolutionary

8 dynamics and can vary among lineages for a variety of genomic and life-history causes (Nam et

9 al. 2010; Nabholz et al. 2011; Romiguier et al. 2010, 2013). Higher GC content in particular

10 lineages of mammals has been associated with lower body mass and smaller genome size

11 (Romiguier et al. 2010). This relationship would predict higher GC content in songbirds than in

12 non-passerines, the opposite pattern that we found here. Higher GC content in specific genes or

13 chromosomal regions can also be an indicator of increased rates of biased-gene conversion

14 (BGC), a neutral process across much of the genome that can ultimately convert T-A base pairs

15 to C-G base pairs (Duret \& Galtier 2009, Romiguier et al. 2010). In avian and other MHC genes,

16 gene conversion and recombination have long been known to diversify the PBR regions (Hess et

17 al. 2002; Spurgin et al. 2011). The weakly higher GC content in the $3^{\text {rd }}$ positions of codons of

18 non-passerine class I genes that we detected here could suggest higher rates of gene conversion

19 in non-passerines. This trend would be somewhat at odds with the higher rates of adaptive

20 evolution observed in songbirds, in so far as gene conversion is thought to be an important

21 source of nonsynonymous mutations in avian MHC genes (Hosomichi et al. 2008). In fact, the

22 lower GC content of $3^{\text {rd }}$ positions that we found here contradicts a genome-wide trend for avian

23 genes in which songbirds typically exhibit higher GC content than do non-passerines (although 
1 this trend has not been examined in large numbers of species; Nabholz et al 2011; N. Backstrom,

2 pers. Comm.). The degree of significance of the higher GC content in $3^{\text {rd }}$ positions of

3 non-passerine class I genes depended on the model used; in standard non-phylogenetic terms, the

4 distinction is highly significant, whereas under a comparative method tailored for continuous

5 phenotypic data, the significance is model-dependent. The study of base compositional variation

6 in avian genes is still in its infancy and the particular base composition of an individual gene

7 may reflect the local rate of recombination in the region of the genome, or it may represent a

8 stochastic effect. Further work in this area is needed.

9 Our analysis suggested that the significance of the difference in GC3 between songbirds

10 and non-passerines depends on the length of the branch leading to songbirds. This branch length

11 will vary depending on the gene or genomic region analyzed, and will also vary depending on

12 the pattern of evolution displayed by the trait being analyzed, since branch lengths in the

13 phylogeny affect the pattern of covariance among species that is consistent with a Brownian

14 motion model (Harvey and Pagel 1991; Garland et al. 2005). The analysis of continuous traits

15 such as base composition in birds will depend on a variety of factors influencing the phylogeny

16 and branch lengths of the species being analyzed. As we enter the era of large-scale comparative

17 studies in birds, attention to these diverse factors will enable maximal resolution of evolutionary

18 dynamics.

\section{Conclusion}

20 The main purpose of this study was testing the capability of a newly designed pair of primers to

21 cross-amplify multiple and evolutionarily relevant MHC loci across a broad spectrum of taxa.

22 The order Passeriformes contains thousands of species. Thus, we believe the rapid diffusion of

23 the primers presented here represents a significant advance for the investigation of MHC 
1 variation across a widely diverse group of birds. That said, future studies must investigate in

2 more depth patterns of MHC class I variation within each particular taxa, including the

3 estimation of the minimum number of putatively functional genes, pseudogenes and the extent of

4 genetic variation and level of expression within different loci. Our primers appear to target

5 polymorphic and functional MHC class I genes, a conclusion also supported by differences in the

6 set of alleles isolated in two house finches and two eastern bluebirds. Additionally, the primers

7 amplify almost the entire coding sequence of exon 3 (only excluding the four first codons, which

8 seem to be largely conserved among songbirds), a fragment that is somewhat longer than that

9 typically amplified in MHC class I studies in birds. We expect these primers to facilitate further

10 work on MHC class I genes of songbirds, for both ecological and molecular evolutionary studies.

\section{Acknowledgements}

13 This research was supported by NSF grant IOS-0923088 to Geoff Hill and SVE. During this

14 research, M.A. was funded by a postdoctoral fellowship from the Ministerio de Ciencia e

15 Innovacion (www.micinn.es) of the Spanish government. We thank Gavin Thomas, Liam

16 Revell, Chris Organ and Andrew Meade for helpful discussion and advice on comparative

17 methods; Niclas Backström for discussion of base composition; and T. Lenz for discussion of

18 MHC issues.

19 References

Abascal F, Zardoya R, Telford MJ. 2010. TranslatorX: multiple alignment of nucleotide sequences guided by amino acid translations. Nucleic Acids Research 38:W7-13

Alcaide M, Edwards SV, Cadahia L, Negro JJ. 2009. MHC class I genes of birds of prey: isolation, polymorphism and diversifying selection. Conservation Genetics 10:1349-1355.

Alcaide M, Edwards SV, Negro JJ. 2007. Characterization, Polymorphism, and Evolution of MHC Class II B Genes in Birds of Prey. Journal of Molecular 
Evolution 65:541-554.

Babik W. 2010. Methods for MHC genotyping in non-model vertebrates. Molecular Ecology Resources 10:237-251.

Balakrishnan CN, Ekblom R, Völker M, Westerdahl H, Godinez R, Kotkiewicz H, Burt DW, Graves T, Griffin DK, Warren WC, Edwards SV. 2010. Gene duplication and fragmentation in the zebra finch major histocompatibility complex. BMC Biology 2010, 8:29.

Barker FK, Cibois A, Schikler P, Feinstein J and Cracraft J. 2004. Phylogeny and diversification of the largest avian radiation. Proceedings of the National Academy of Sciences. 101: 11040-11045.

Barker, F.K., G.F. Barrowclough, and J. G. Groth. 2002. A phylogenetic hypothesis for passerine birds: taxonomic and biogeographic implications of an analysis of nuclear DNA sequence data. Proceedings of the Royal Society of London, Series B 269: 295-308.

Bielawski JP and Yang Z. 2004. A maximum likelihood method for detecting functional divergence at individual codon sites, with application to gene family evolution. Journal of Molecular Evolution 59:121-132.

Bjorkman PJ, Saper MA, Samraoui B, Bennett WS, Strominger JL, Wiley DC. 1987. The foreign antigen binding site and $\mathrm{T}$ cell recognition regions of class I histocompatibility antigens. Nature 329:512-518.

Bollmer JL, Dunn PO, Freeman-Gallant CR, Whittingham LA. 2012. Social and extra-pair mating in relation to major histocompatibility complex variation in common yellowthroats. Proceedings of the Royal Society B-Biological Sciences 279:4778-4785.

Bollmer JL, Dunn PO, Whittingham LA, Wimpee C. 2010. Extensive MHC Class II B Gene Duplication in a Passerine, the Common Yellowthroat (Geothlypis trichas). Journal of Heredity 101:448-460.

Bonneaud C, Sorci G, Morin V, et al. 2004. Diversity of Mhc class I and IIB genes in house sparrows (Passer domesticus). Immunogenetics 55:855-865.

Burri R, Hirzel HN, Salamin N, Roulin A, Fumagalli L .2008. Evolutionary patterns of $\mathrm{MHC}$ class IIB in owls and their implications for the understanding of avian MHC evolution. Molecular Biology and Evolution 25:1180-1191.

Canal D, Alcaide M, Anmarkrud JA, Potti J .2010. Towards the simplification of MHC typing protocols: targeting classical $\mathrm{MHC}$ class II genes in a passerine, the pied flycatcher Ficedula hypoleuca. BMC Research Notes 3:236.

Cloutier A, Mills JA, Baker AJ. 2011. Characterization and locus-specific typing of MHC class I genes in the red-billed gull (Larus scopulinus) provides evidence for major, minor, and nonclassical loci. Immunogenetics 63:377-394.

de Bakker PIW, Raychaudhuri S. 2012. Interrogating the major histocompatibility complex with high-throughput genomics. Human Molecular Genetics 21:R29-R36.

Duret L and Galtier N. 2009. Biased Gene Conversion and the Evolution of Mammalian Genomic Landscapes. Annual Review of Genomics and Human Genetics 10:285-311.

Drummond AJ, Ashton B, Buxton, S, Cheung B, Cooper A, Duran, C, Field, M et al. 2011. Geneious R6, Available from http://www.geneious.com/. 


\section{Edgar RC. 2004. MUSCLE: multiple sequence alignment with high accuracy and high throughput. Nucleic Acids Research 32:1792-1797. \\ Eizaguirre C, Lenz TL, Kalbe M, Milinski M. 2012. Rapid and adaptive evolution of MHC genes under parasite selection in experimental vertebrate populations. Nature Communications 3:621. \\ Ekblom, R., J. Stapley, A. D. Ball, T. Birkhead, T. Burke, and J. Slate. 2011. Genetic mapping of the major histocompatibility complex in the zebra finch (Taeniopygia guttata). Immunogenetics 63: 523-530. \\ Ekblom R, Sæther SA, Grahn M, Fiske P, Kålås JA \& Höglund J. 2004. MHC variation and mate choice in a lekking bird, the great snipe (Gallinago media). Molecular Ecology 13:3821-3828.}

Ekblom R, Grahn M, Hoglund J. 2003. Patterns of polymorphism in the MHC class II of a non-passerine bird, the great snipe (Gallinago media). Immunogenetics 54:734-741.

Gangoso L, Alcaide M, Grande JM, et al. 2012. Colonizing the world in spite of reduced MHC variation. Journal of Evolutionary Biology 25:1438-1447.

Garland, T., A. F. Bennett, and E. L. Rezende. 2005. Phylogenetic approaches in comparative physiology. J Exp Biol 208:3015-3035.

Guindon S, JF Dufayard, V. Lefort, M. Anisimova, W. Hordijk, O. Gascuel. New algorithms and methods to estimate maximum-likelihood phylogenies: assessing the performance of PhyML 3.0. Systematic Biology 2010. 59: 307-321.

Hall T. 1999. BioEdit: a user-friendly biological sequence alignment editor and analysis program for Windows 95/98/NT. Nucleic Acid Symposium Series 41: 95-98.

Harvey, P. H., and M. D. Pagel. 1991. The Comparative Method in Evolutionary Biology. Oxford, Oxford University Press.

Hess CM, Edwards SV. 2002. The evolution of the major histocompatibility complex in birds. Bioscience 52:423-431.

Hosomichi K, Miller MM, Goto RM, Wang YJ, Suzuki S, Kulski JK, Nishibori M et al. 2008. Contribution of mutation, recombination, and gene conversion to chicken Mhc-B haplotype diversity. Journal of Immunology 181:3393-3399.

Iwasaki A, Medzhitov R. 2010. Regulation of Adaptive Immunity by the Innate Immune System. Science 327:291-295.

Juola FA, Dearborn DC. 2011. Sequence-based evidence for major histocompatibility complex-disassortative mating in a colonial seabird. Proceedings of the Royal Society B-Biological Sciences 279:153-162.

Kamath PL, Getz WM. 2011. Adaptive molecular evolution of the Major Histocompatibility Complex genes, DRA and DQA, in the genus Equus. Bmc Evolutionary Biology 11:128.

Knafler GJ, Clark JA, Dee Boersma P, Bouzat JL. 2012. MHC Diversity and Mate Choice in the Magellanic Penguin, Spheniscus magellanicus. Journal of Heredity 103:759-768.

Kubinak JL, Ruff JS, Hyzer CW, Slev PR, Potts WK. 2012. Experimental viral evolution to specific host MHC genotypes reveals fitness and virulence trade-offs in alternative MHC types. Proceedings of the National Academy of Sciences of the United States of America 109:3422-3427.

Lenz TL, Becker, S. 2008. Simple approach to reduce PCR artefact formation leads to reliable genotyping of $\mathrm{MHC}$ and other highly polymorphic loci - implications for 
evolutionary analysis. Gene 427:117-123.

Li L, Zhou XP, Chen XL. 2011. Characterization and Evolution of MHC Class II B Genes in Ardeid Birds. Journal of Molecular Evolution 72:474-483.

Loiseau C, Zoorob R, Garnier S, et al. 2008. Antagonistic effects of a Mhc class I allele on malaria-infected house sparrows. Ecology Letters 11:258-265.

Nabholz B, Kunstner A, Wang R, Jarvis, ED and Ellegren H. 2011. Dynamic Evolution of Base Composition: Causes and Consequences in Avian Phylogenomics. Molecular Biology and Evolution 28:2197-2210 (2011).

Nam K, Mugal C, Nabholz B, Schielzeth H, Wolf JBW, Backström N, et al. 2010. Molecular evolution of genes in avian genomes. Genome Biology 11: R68-R68.

Piertney SB, Oliver MK. 2006. The evolutionary ecology of the major histocompatibility complex. Heredity 96: 7-21.

Posada D, Crandall KA. 1998. Modeltest: testing the model of DNA substitution. Bioinformatics 14: 817-818.

Promerova M, Albrecht T, Bryja J. 2009. Extremely high MHC class I variation in a population of a long-distance migrant, the Scarlet Rosefinch (Carpodacus erythrinus). Immunogenetics 61:451-461.

Radwan J, Biedrzycka A, Babik W. 2010. Does reduced MHC diversity decrease viability of vertebrate populations? Biological Conservation 143:537-544.

Radwan J, Zagalska-Neubauer M, Cichon M, et al. 2012. MHC diversity, malaria and lifetime reproductive success in collared flycatchers. Molecular Ecology 21:2469-2479.

Romiguier J, Ranwez V, Douzery EJP and Galtier N. 2010. Contrasting GC-content dynamics across 33 mammalian genomes: relationship with life-history traits and chromosome sizes. Genome research 20:1001-9.

Romiguier, J, V Ranwez, E J P Douzery, and N Galtier. 2013. "Genomic evidence for large, long-lived ancestors to placental mammals." Molecular Biology and Evolution 30(1): 5-13.

Saitou N, Nei M. 1987. The neighbor-joining method: a new method for reconstructing phylogenetic trees. Molecular Biology and Evolution 4:406-425.

Sanderson MJ. 2002. Estimating Absolute Rates of Molecular Evolution and Divergence Times: A Penalized Likelihood Approach. Molecular Biology and Evolution 19:101-109.

Saper MA, Bjorkman PJ, Wiley DC. 1991. Refined structure of the human histocompatibility antigen HLA-A2 at 2.6 ^ resolution. Journal of Molecular Biology 219:277-319

Sepil I, Moghadam HK, Huchard E, Sheldon BC. 2012. Characterization and 454 pyrosequencing of Major Histocompatibility Complex class I genes in the great tit reveal complexity in a passerine system. BMC Evolutionary Biology 12:68.

Silva MC, Edwards SV. 2009. Structure and Evolution of a New Avian MHC Class II B Gene in a Sub-Antarctic Seabird, the Thin-Billed Prion (Procellariiformes: Pachyptila belcheri). Journal of Molecular Evolution 68:279-291.

Sommer S. 2005. The importance of immune gene variability (MHC) in evolutionary ecology and conservation. Frontiers In Zoology 2:16.

Spurgin LG, van Oosterhout C, Illera JC, et al. 2011. Gene conversion rapidly generates 
major histocompatibility complex diversity in recently founded bird populations. Molecular Ecology 20: 5213-5225.

Strandh M, Westerdahl H, Pontarp M, Canbäck B, Dubois MP, Miquel C, Taberlet

P, Bonadonna F. 2012. Major histocompatibility complex class II compatibility, but not class I, predicts mate choice in a bird with highly developed olfaction. Proceedings of the Royal Society B-Biological Sciences 279:4457-63.

Strandh M, Lannefors M, Bonadonna F, Westerdahl H. 2011. Characterization of MHC class I and II genes in a subantarctic seabird, the blue petrel, Halobaena caerulea (Procellariiformes). Immunogenetics 63:653-666.

Swofford DL. 2002. PAUP*. Phylogenetic Analysis Using Parsimony (*and Other Methods). Version 4. Sinauer Associates, Sunderland, Massachusetts.

Takahata, N. 1990. A simple genealogical structure of strongly balanced allelic lines and trans-species evolution of polymorphism. Proc Natl Acad Sci USA 87:2419-2423.

Tamura K, Peterson D, Peterson N, Stecher G, Nei M, Kumar S. 2011. MEGA5: molecular evolutionary genetics analysis using maximum likelihood, evolutionary distance, and maximum parsimony methods. Molecular Biology and Evolution 28: 2731-2739.

Thomas G and Freckleton R. 2012. Models of Trait Macroevolution on Trees. R package. Downloaded from the $\mathrm{R}$ CRAN repository.

Thomas GH, Meiri S, and Phillimore AB. 2009. Body size diversification in Anolis: novel environments and island effects. Evolution 63:2017-2030.

Thomas GH, Freckleton RP, \& Szekely T. 2006. Comparative analyses of the influence of developmental mode on phenotypic diversification rates in shorebirds. Proceedings of the Royal Society B 273, 1619-1624.

van Oosterhout C. 2009. Trans-species polymorphism, HLA-disease associations and the evolution of the MHC. Communicative \& Integrative Biology 2:408-410.

Welch JJ, Bininda-Emonds ORP, Bromham L 2008. Correlates of substitution rate variation in mammalian protein-coding sequences. BMC Evol. Biol. 8: e53.

Westerdahl H, Asghar M, Hasselquist D and Bensch S. 2012. Quantitative disease resistance: to better understand parasite-mediated selection on major histocompatibility complex. Proceedings of the Royal Society B-Biological Sciences 279: 577-584.

Westerdahl H. 2007. Passerine MHC: genetic variation and disease resistance in the wild. Journal of ornithology, 148, 469-477.

Westerdahl H. 2004. No evidence of an MHC-based female mating preference in great reed warblers. Molecular Ecology 13:2465-70.

Westerdahl H, Wittzell H, von Schantz T and Bensch S. 2004. MHC class I typing in a songbird with numerous loci and high polymorphism using motif-specific PCR and DGGE. Heredity, 92, 534-542.

Yang Z, Wong, WSW and Nielsen R. 2005. Bayes empirical Bayes inference of amino acid sites under positive selection. Molecular Biology and Evolution 22:1107-1118.

Yang, Z. 2007. PAML 4: a program package for phylogenetic analysis by maximum likelihood. Molecular Biology and Evolution 24:1586-1591 
1 Zagalska-Neubauer M, Babik W, Stuglik M, et al. 2010. 454 sequencing reveals 2 extreme complexity of the class II Major Histocompatibility Complex in the 3 collared flycatcher. Bmc Evolutionary Biology 10:395. 


\section{FIGURES}

2 FIGURE 1. Schematic representation of part of an MHC class I gene. Arrows indicate the

3 location of the primers used in this study. Both the coding sequences of exon 2 and exon 3

4 comprise the antigen-binding region of MHC class I molecules. Exons are represented by boxes

5 and the lines connecting boxes represent introns.

6 FIGURE 2. Neighbor-joining tree of the passerine MHC class I sequences (exon 3) here isolated 7 plus additional exon 3 sequences isolated in other avian species. Bootstrap support for the main 8 branches of the tree are indicated. A more detailed depiction of this tree is provided in 9 Supplementary figure 1.

10 FIGURE 3. Neighbor-net network of the MHC class I sequences (exon 3, N=120) isolated from the 16 songbird species investigated in this study. Only the main clusters of sequences are labeled for simplicity. Those species whose sequences fall into a single cluster are indicated by asterisks.

14 FIGURE 4. Distribution of positively selected sites in exon 3 of songbird class I genes as estimated by PAML (model 2). Red columns indicate the class of sites with a high probability of $\omega>1$. In this model $\omega_{1}=0.25$ and applies to $\sim 59.3 \%$ of the codons (blue); $\omega_{2}=1$ at $\sim 28.2 \%$ of the sites (green); and $\omega_{3}=3.53$ at $\sim 12.6 \%$ of the sites (red). Asterisks indicate codons assumed to comprise the avian PBR in the MEGA analysis and crosses indicate PBR residues in the human HLA-A2 molecule (Björkman et al. 1987, Saper et al. 1991). FIGURE 5. Base compositional variation in the $3^{\text {rd }}$ codon position of avian class I MHC genes (exon 3). Clades are indicated according to the key provided. The topology depicted here is a neighbor-joining tree as described in Methods, however the branch lengths have been ultrametricized as described in Methods to conduct the comparative tests. The branch leading to songbirds is indicated. The topology of this tree differs slightly from that in Fig. 2 because this is a simple neighbor-joining tree, rather than a bootstrap consensus of trees as in Fig. 2. 


\section{SUPPLEMENTARY MATERIAL}

2 SUPPLEMENTARY FILES

3 SUPPLEMENTARY FILE 1 (.txt). Alignment of the MHC class I sequences (exon 3) isolated

4 in this study (in fasta format) plus additional homologous sequences from other avian species

5 download from the GenBank database. Genbank accession numbers of sequences determined in

6 this study are given in Supplementary file 2.

7 SUPPLEMENTARY FILE 2 (.txt). GenBank accession numbers assigned to each of the MHC

8 class I sequences isolated in the present study.

9 SUPPLEMENTARY FIGURES

10 SUPPLEMENTARY FIGURE 1. Neighbor-joining tree (at high resolution and including all

11 branch labels) of the passerine MHC class I sequences (exon 3) here isolated plus additional exon 3 sequences isolated in other avian species. 


\section{Table $\mathbf{1}_{\text {(on next page) }}$}

Amplification success and genetic variability within each of the 16 oscine songbird and two suboscine species here investigated. 
TABLE 1. Amplification success and genetic variability within each of the 16 oscine songbird and two suboscine species here investigated. The table shows the putative number of functional alleles per species ( $\mathrm{Na}$; the number of putative pseudogene sequences, if any, is given in parentheses), the overall number of polymorphic sites per allele repertoire (S), average nucleotide diversity $(\pi)$ and average number of nucleotide differences $(k)$ among the sequences isolated from the same species. This table also shows the ratio $(\omega)$ between non-synonymous $\left(d_{n}\right)$ and synonymous $\left(d_{s}\right)$ substitution rates for those codons presumably comprising (PBR) and non-comprising (non-PBR) the peptide binding region of the MHC class I molecule (see text for details). Sample sizes are 1 for all species except for Eastern Bluebird and House Finch, for which $n=2$. The accession numbers for the specimens from the Museum of Comparative Zoology (MCZ) from which DNA was isolated are given. n/a, not accessioned. --, no amplification.

\begin{tabular}{|c|c|c|c|c|c|c|c|c|c|}
\hline Latin Name & Common Name & Family & MCZ no. & $\mathrm{Na}$ & $\mathbf{s}$ & $\pi$ & $\mathrm{K}$ & $\begin{array}{c}\omega= \\
d_{n} / d_{s} \\
\text { PBR }\end{array}$ & $\begin{array}{l}\omega= \\
d_{n} / d_{s} \\
\text { non- } \\
\text { PBR }\end{array}$ \\
\hline Passer & & & & & & & 25.8 & & \\
\hline $\begin{array}{l}\text { domesticus } \\
\text { Cardinalis }\end{array}$ & House sparrow & Passeridae & 337599 & 8 & 56 & 0.1 & 6 & 3.69 & 0.53 \\
\hline $\begin{array}{l}\text { cardinalis } \\
\text { Thraupis }\end{array}$ & Northern cardinal & Cardinalidae & 337661 & 7 & $\begin{array}{l}68 \\
10\end{array}$ & 0.124 & $\begin{array}{l}32.9 \\
41.8\end{array}$ & 3.08 & 0.45 \\
\hline $\begin{array}{l}\text { episcopus } \\
\text { Bombycilla }\end{array}$ & Blue-grey tanager & $\begin{array}{l}\text { Thraupidae } \\
\text { Bombycillida }\end{array}$ & 337677 & $8(3)$ & 3 & 0.16 & 2 & 4.16 & 0.74 \\
\hline $\begin{array}{l}\text { cedrorum } \\
\text { Agelaius }\end{array}$ & $\begin{array}{l}\text { Cedar waxwing } \\
\text { Red-winged }\end{array}$ & e & 337636 & 9 & 52 & 0.086 & 22.7 & 1.02 & 0.31 \\
\hline $\begin{array}{l}\text { phoeniceus } \\
\text { Sturnus }\end{array}$ & blackbird & Icteridae & 337415 & 8 & $\begin{array}{l}63 \\
10\end{array}$ & 0.105 & $\begin{array}{l}27.5 \\
42.4\end{array}$ & 6.83 & 0.79 \\
\hline $\begin{array}{l}\text { vulgaris } \\
\text { Thryothorus }\end{array}$ & $\begin{array}{l}\text { European starling } \\
\text { Stripe-breasted }\end{array}$ & $\begin{array}{l}\text { Sturnidae } \\
\text { Troglodytida }\end{array}$ & 337556 & 9 & 8 & 0.162 & $\begin{array}{c}4 \\
28.4\end{array}$ & 2.46 & 0.58 \\
\hline $\begin{array}{c}\text { thoracicus } \\
\text { Turdus }\end{array}$ & wren & e & 337696 & $6(3)$ & 56 & 0.107 & $\begin{array}{c}20.4 \\
7\end{array}$ & 7.12 & 0.72 \\
\hline $\begin{array}{l}\text { migratorius } \\
\text { Geothlypis }\end{array}$ & $\begin{array}{l}\text { American robin } \\
\text { Common }\end{array}$ & Turdidae & 337189 & $3(3)$ & 56 & 0.145 & 33.8 & 1.89 & 0.69 \\
\hline $\begin{array}{c}\text { trichas } \\
\text { Dumetella }\end{array}$ & yellowthroat & Parulidae & 337642 & 5 & 63 & 0.133 & 34.8 & 3.72 & 0.47 \\
\hline $\begin{array}{c}\text { carolinensis } \\
\text { Passerina }\end{array}$ & Gray catbird & Mimidae & 337601 & 5 & 66 & 0.129 & $\begin{array}{l}33.7 \\
35.7\end{array}$ & 1.56 & 0.65 \\
\hline $\begin{array}{l}\text { cyanea } \\
\text { Polioptila }\end{array}$ & $\begin{array}{l}\text { Indigo bunting } \\
\text { Tropical }\end{array}$ & Cardinalidae & 337535 & 10 & 88 & 0.137 & $\begin{array}{c}8 \\
14.6\end{array}$ & $\begin{array}{c}2.79 \\
0.21 / 0.0\end{array}$ & 0.45 \\
\hline plumbea & Gnatcatcher & Polioptilidae & 337547 & 6 & 33 & 0.056 & $\begin{array}{c}7 \\
43.6\end{array}$ & 0 & 1.07 \\
\hline $\begin{array}{c}\text { Vireo olivaceus } \\
\text { Sitta }\end{array}$ & $\begin{array}{l}\text { Red-eyed vireo } \\
\text { Red-breasted }\end{array}$ & Vireonideae & 337166 & 6 & 92 & 0.165 & 7 & $\begin{array}{c}3.53 \\
0.13 / 0.0\end{array}$ & 0.76 \\
\hline canadensis & nuthatch & Sittidae & 337181 & 6 & 34 & 0.057 & 15 & 0 & 0.63 \\
\hline $\begin{array}{l}\text { Sialia sialis } \\
\text { Haemorhous }\end{array}$ & Eastern bluebird & Turdidae & $\mathrm{n} / \mathrm{a}$ & 13 & 80 & 0.129 & 33.8 & 0.91 & 0.40 \\
\hline $\begin{array}{l}\text { mexicanus } \\
\text { Sayornis }\end{array}$ & House finch & Fringillidae & $\mathrm{n} / \mathrm{a}$ & 11 & 85 & 0.149 & 38.8 & 5.03 & 0.65 \\
\hline $\begin{array}{l}\text { phoebe } \\
\text { Manacus }\end{array}$ & $\begin{array}{l}\text { Eastern Phoebe } \\
\text { White-Collared }\end{array}$ & Tyrannidae & 337162 & -- & -- & -- & -- & -- & -- \\
\hline candei & Manakin & Pipridae & 348105 & -- & -- & -- & -- & -- & -- \\
\hline
\end{tabular}




\section{Table $2_{\text {(on next page) }}$}

Estimates of non-synonymous $\left(\mathrm{d}_{\mathrm{n}}\right)$ and synonymous $\left(\mathrm{d}_{\mathrm{s}}\right)$ substitution rates and their ratio for codons chosen a priori to comprise (PBR) and not comprise (non-PBR) the peptide binding region of the MHC class I molecule (MEGA) and for codon 
TABLE 2. Estimates of non-synonymous $\left(d_{n}\right)$ and synonymous $\left(d_{s}\right)$ substitution rates and their ratio for codons chosen a priori to comprise (PBR) and not comprise (non-PBR) the peptide binding region of the MHC class I molecule (MEGA) and for codon classes estimated from the data (PAML). For each comparison estimates for songbirds (oscine passerines) and non-passerines are provided (see also Fig. 2). For the MEGA estimates, standard errors based on 1,000 bootstrap replicates are given. For the PAML estimates, the results of two models ( $C$ and $D)$ are given. In models $C$ and $D$, $\omega_{0}$ is constrained to fall below 1 , whereas in model $C, \omega_{1}$ must equal 1.

\begin{tabular}{|c|c|c|c|c|c|}
\hline & $\begin{array}{l}\text { Site } \\
\text { class }\end{array}$ & $\begin{array}{l}\text { Parameter } \\
\star\end{array}$ & $\begin{array}{l}\text { Proportion of } \\
\text { sites }\end{array}$ & \multirow{2}{*}{\multicolumn{2}{|c|}{$\begin{array}{l}\text { Clade } \\
\text { Non-Passeriform }\end{array}$}} \\
\hline \multirow{13}{*}{ MEGA } & \multirow{7}{*}{ PBR } & & & & \\
\hline & & & & Songbirds & es \\
\hline & & & & $0.620 \pm$ & \\
\hline & & $d_{n}$ & 0.791 & 0.157 & $0.474 \pm 0.129$ \\
\hline & & & & $0.163 \pm$ & \\
\hline & & $d_{s}$ & 0.209 & 0.074 & $0.246 \pm 0.111$ \\
\hline & & $\omega=d_{n} / d_{s}$ & & 3.80 & 1.92 \\
\hline & non-PBR & $d_{n}$ & 0.769 & $\begin{array}{c}0.144 \pm \\
0.017\end{array}$ & $0.135 \pm 0.022$ \\
\hline & & & & $\begin{array}{c}0.255 \pm \\
0.041\end{array}$ & $0.284+0.047$ \\
\hline & & $\omega=d_{n} / d_{s}$ & & 0.56 & 0.48 \\
\hline & $\begin{array}{c}\text { All } \\
\text { codons }\end{array}$ & $d_{n}$ & 0.772 & $\begin{array}{c}0.176 \pm \\
0.025 \\
0.245+\end{array}$ & $0.160 \pm 0.024$ \\
\hline & & $d_{s}$ & 0.228 & 0.037 & $0.278 \pm 0.044$ \\
\hline & & $\omega=d_{n} / d_{s}$ & & 0.72 & 0.58 \\
\hline $\begin{array}{l}\text { PAML } \\
\text { Model }\end{array}$ & & & & & \\
\hline$A$ & 0 & $0<\omega_{0}<1$ & 0.546 & 0.230 & 0.230 \\
\hline & 1 & $\begin{array}{l}\omega_{1}=1 \\
\omega_{2} \geq 1\end{array}$ & 0.301 & 1.000 & 1.000 \\
\hline & $2 a$ & $0<\omega_{0}<1$ & 0.991 & 2.479 & 0.230 \\
\hline & $2 b$ & $\begin{array}{l}\omega_{2} \geq 1 \\
\omega_{1}=1\end{array}$ & 0.055 & 2.479 & 1.000 \\
\hline Model & & & & & \\
\hline C & 0 & $0<\omega_{0}<1$ & 0.380 & 0.111 & 0.111 \\
\hline & 1 & $\omega_{1}=1$ & 0.120 & 1.000 & 1.000 \\
\hline & 2 & $\omega_{2}$ & 0.500 & 0.476 & 0.421 \\
\hline Model & 0 & $0<\omega_{0}<1$ & 0.381 & 0.141 & 0.141 \\
\hline
\end{tabular}


D

$\begin{array}{lllll}1 & \omega_{1} & 0.098 & 2.388 & 2.388\end{array}$

$\begin{array}{lllll}2 & \omega_{2} & 0.521 & 2.388 & 0.633\end{array}$

*For the PAML models, when two parameters are listed in the column, the first parameter in the cell refers to the songbird branch (model A) or clade (model C or D), and the second refers to the non-passerine branch or clade. 


\section{Table 3 (on next page)}

Tests of differences in mean base composition and rates of base compositional change in MHC classs I genes (exon 3) between songbirds and non-passerines using the likelihood model of Thomas et al. 2009. 
TABLE 3. Tests of differences in mean base composition and rates of base compositional change in MHC classs I genes (exon 3) between songbirds and non-passerines using the likelihood model of Thomas et al. 2009. The cells in bold and underlined indicate the model and AIC value that best explains the data under two sets of branch lengths leading to the songbird sequences.

\begin{tabular}{|c|c|c|c|c|c|c|c|c|c|}
\hline \multirow[b]{2}{*}{ Model } & & \multicolumn{4}{|c|}{ proportion GC - all sites } & \multicolumn{4}{|c|}{ proportion GC $-3^{\text {rd }}$ positions } \\
\hline & $\begin{array}{c}\text { Lengt } \\
\mathrm{h} \text { of } \\
\text { songb } \\
\text { ird } \\
\text { branc } \\
\mathrm{h}\end{array}$ & AIC & $\begin{array}{l}\text { Brow } \\
\text { nian } \\
\text { varian } \\
\text { ce }\end{array}$ & $\begin{array}{c}\text { Relative } \\
\text { rates } \\
\text { (songbi } \\
\text { rds, } \\
\text { non-pas } \\
\text { serines) }\end{array}$ & $\begin{array}{c}\text { Estimate } \\
\text { d means } \\
\text { (songbird } \\
\text { s, } \\
\text { non-pass } \\
\text { erines) }\end{array}$ & AIC & $\begin{array}{c}\text { Brow } \\
\text { nian } \\
\text { varian } \\
\text { ce }\end{array}$ & $\begin{array}{c}\text { Relative } \\
\text { rates } \\
\text { (songbi } \\
\text { rds, } \\
\text { non-pas } \\
\text { serines) }\end{array}$ & $\begin{array}{l}\text { Estimate } \\
\text { d means } \\
\text { (songbir } \\
\text { ds, } \\
\text { non-pas } \\
\text { serines) }\end{array}$ \\
\hline $\begin{array}{l}\text { Same } \\
\text { mean, } \\
\text { same } \\
\text { rates }\end{array}$ & Full & $\frac{712 .}{\underline{42}}$ & 22.55 & 1,1 & 56.01 & $\frac{993.5}{4}$ & 78.67 & 1,1 & 72.28 \\
\hline $\begin{array}{l}\text { Different } \\
\text { mean, } \\
\text { same } \\
\text { rates }\end{array}$ & Full & $\begin{array}{c}714 . \\
24\end{array}$ & 22.63 & 1,1 & $\begin{array}{c}55.79,56.7 \\
9\end{array}$ & $\begin{array}{c}993.7 \\
5\end{array}$ & 78.39 & 1,1 & $\begin{array}{c}73.55,67 \\
84\end{array}$ \\
\hline $\begin{array}{l}\text { Same } \\
\text { mean, }\end{array}$ & Full & $\begin{array}{c}714 . \\
35\end{array}$ & 22.08 & $1.05,1$ & 56.02 & $\begin{array}{c}995.4 \\
3\end{array}$ & 80.68 & $0.94,1$ & 72.33 \\
\hline
\end{tabular}




\begin{tabular}{|c|c|c|c|c|c|c|c|c|c|}
\hline \multicolumn{10}{|l|}{$\begin{array}{l}\text { Different } \\
\text { rates }\end{array}$} \\
\hline $\begin{array}{l}\text { Different } \\
\text { mean, } \\
\text { different }\end{array}$ & Full & 716. & & & 55.79, & 995.6 & & & $73.55,67$. \\
\hline rates & & 16 & 22.16 & $1.05,1$ & 56.79 & 5 & 80.27 & $0.94,1$ & 84 \\
\hline $\begin{array}{l}\text { Same } \\
\text { mean, } \\
\text { same }\end{array}$ & Half & 712. & & & & 993.8 & & & \\
\hline rates & & $\underline{03}$ & 22.56 & 1,1 & 56.11 & 8 & 78.96 & 1,1 & 71.69 \\
\hline $\begin{array}{l}\text { Different } \\
\text { mean, } \\
\text { same }\end{array}$ & Half & 713. & & & $55.79,56.7$ & 993.2 & & & 73.55 .67$. \\
\hline rates & & 76 & 22.63 & 1,1 & 9 & $\underline{7}$ & 78.39 & 1,1 & 84 \\
\hline $\begin{array}{l}\text { Same } \\
\text { mean, } \\
\text { different }\end{array}$ & Half & 713. & & & & 995.7 & & & \\
\hline rates & & 96 & 22.10 & $1.05,1$ & 56.12 & 8 & 80.89 & $0.94,1$ & 71.76 \\
\hline $\begin{array}{l}\text { Different } \\
\text { mean, } \\
\text { different }\end{array}$ & Half & 715. & & & $55.76,56.7$ & 995.1 & & & $73.55,67$ \\
\hline rates & & 69 & 22.17 & $1.05,1$ & 9 & 7 & 80.32 & $0.94,1$ & 84 \\
\hline
\end{tabular}




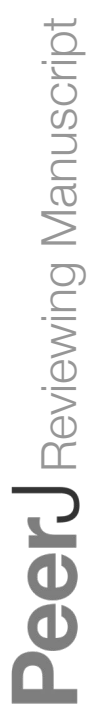




\section{Figure 1}

Schematic representation of part of an MHC class I gene. Arrows indicate the location of the primers used in this study

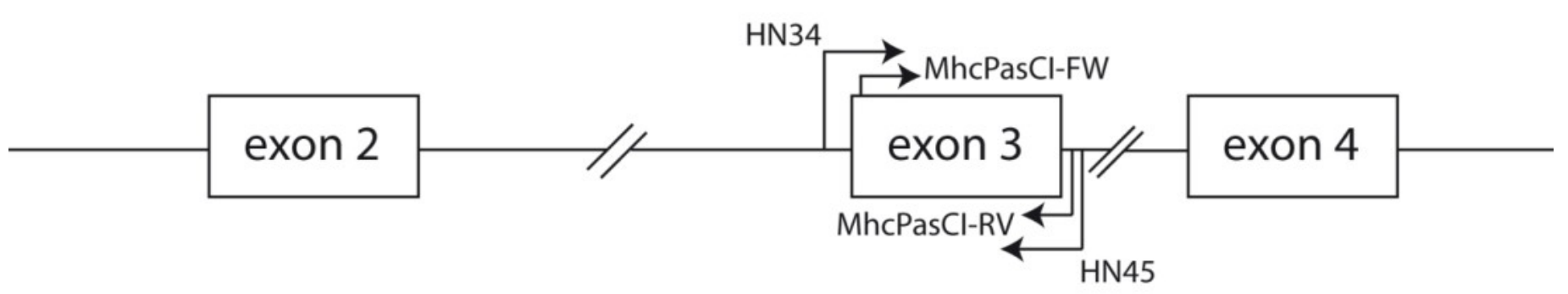




\section{Figure 2}

Neighbor-joining tree of the passerine MHC class I sequences (exon 3) here isolated plus additional exon 3 sequences isolated in other avian species

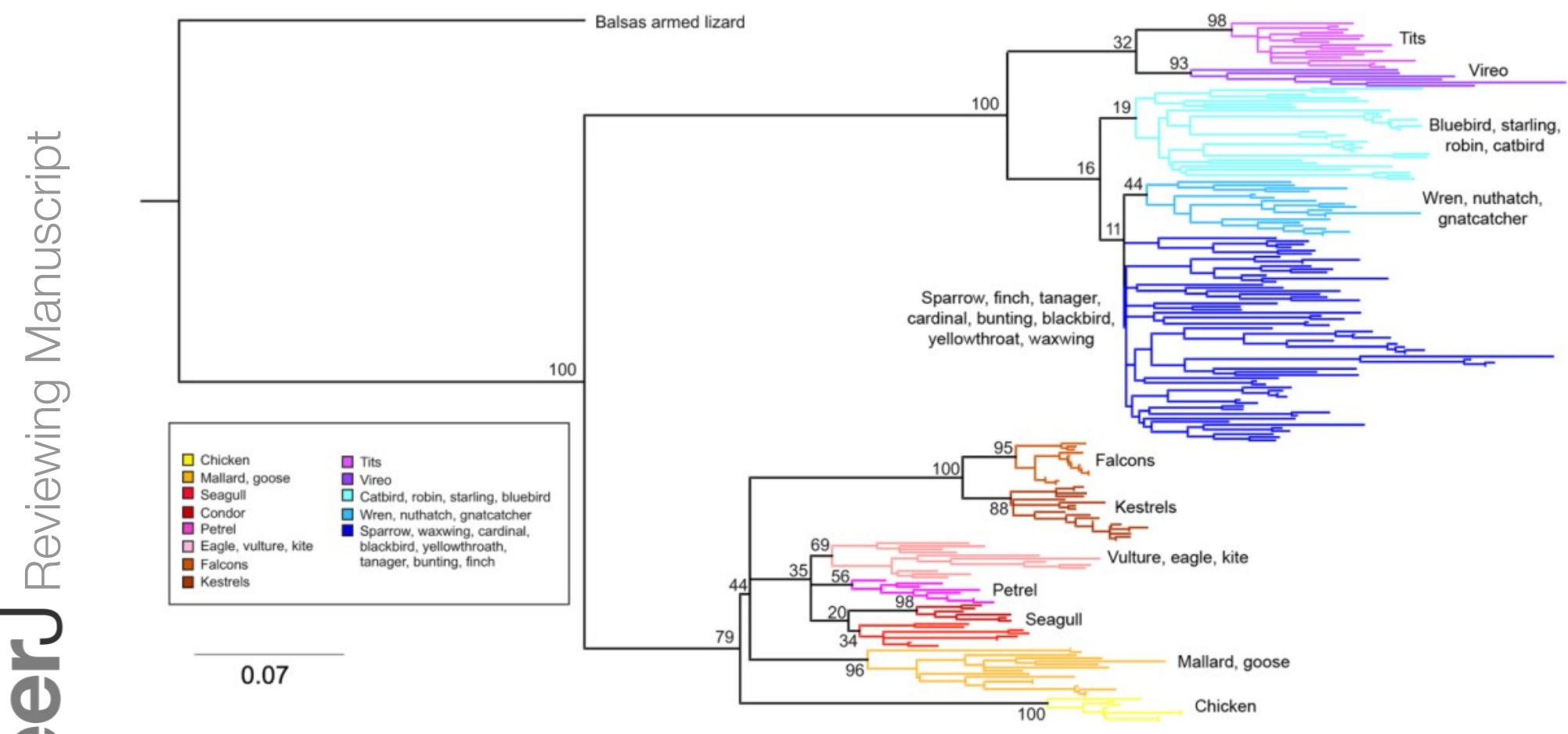




\section{Figure 3}

Neighbor-net network of the MHC class I sequences (exon 3, N=120) isolated from the 16 songbird species investigated in this study.

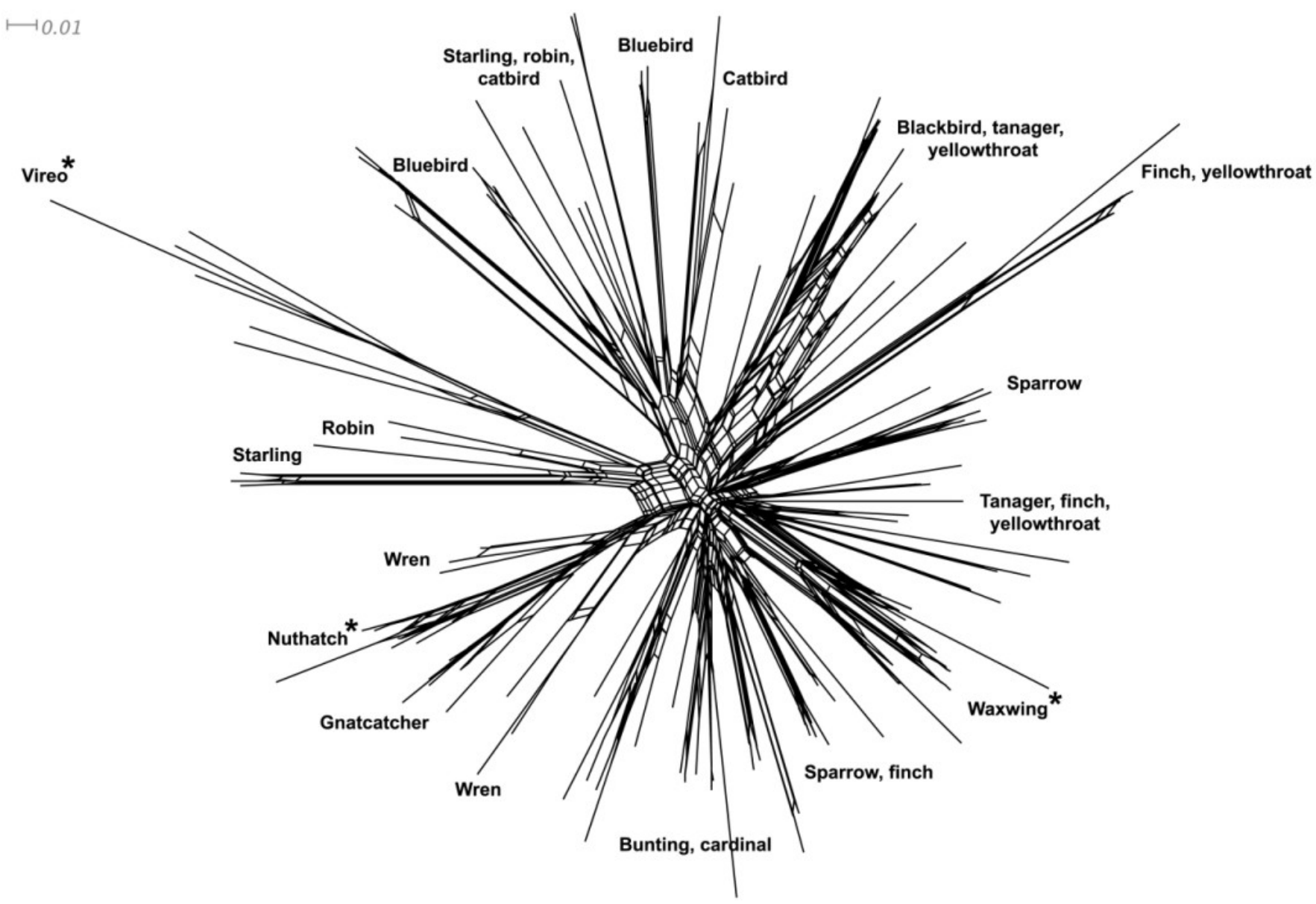




\section{Figure 4}

Distribution of positively selected sites in exon 3 of songbird class I genes as estimated by PAML (model 2).

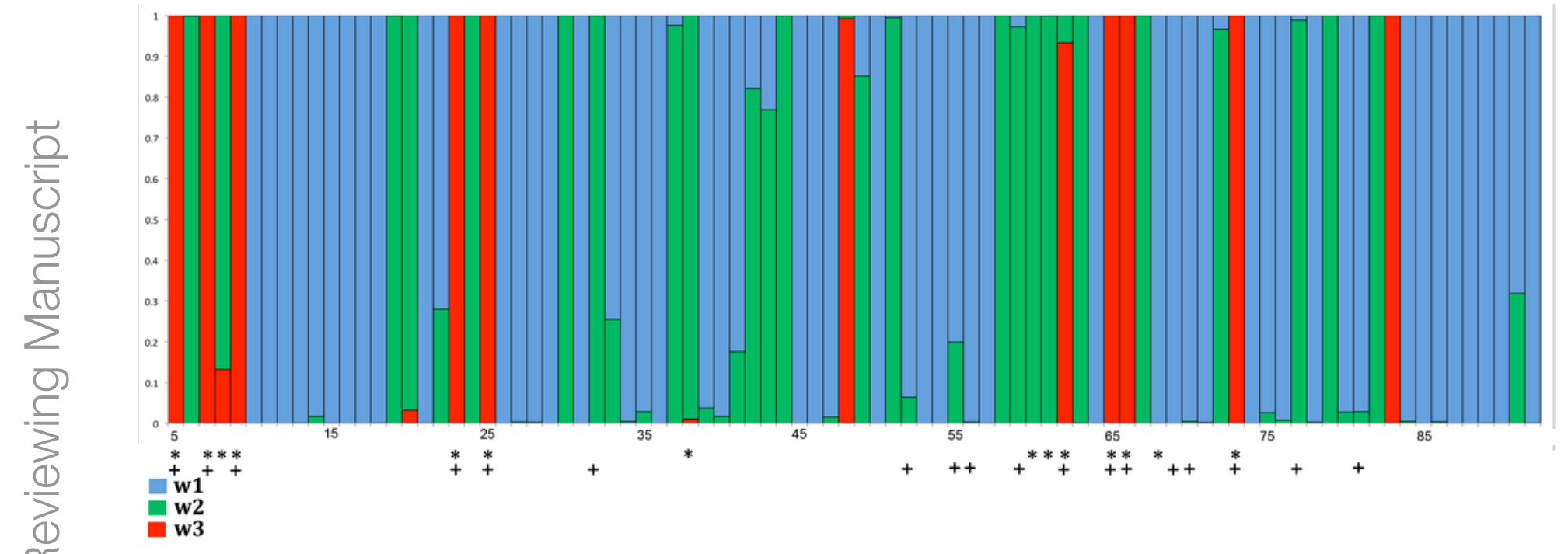




\section{Figure 5}

Base compositional variation in the $3^{\text {rd }}$ codon position of avian class I MHC genes (exon 3).

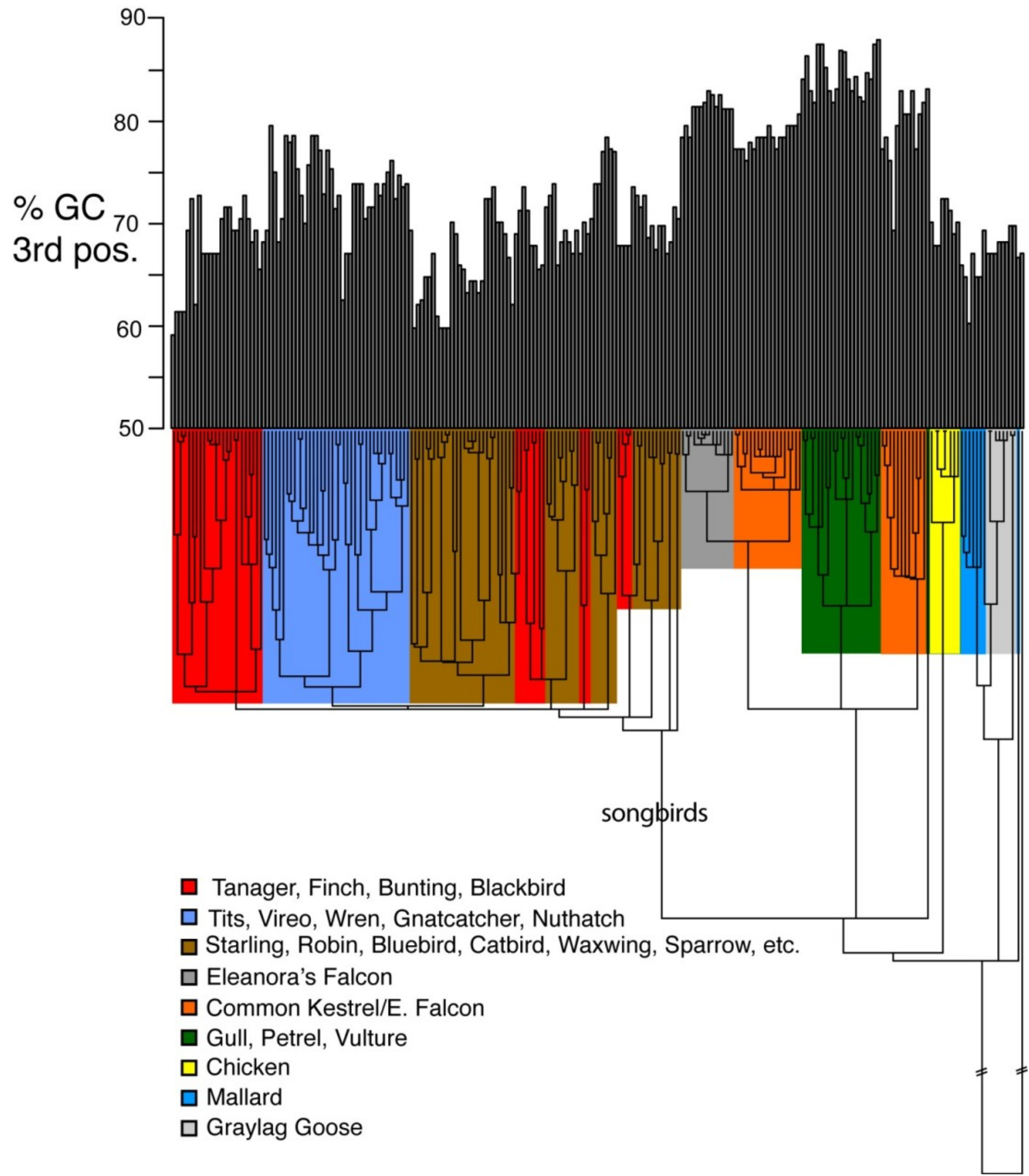

